\title{
Systematic Relationships of New Zealand Endemic Brassicaceae Inferred from nrDNA ITS Sequence Data
}

\author{
ANTHONY D. MitcheLL \\ Ecology and Entomology Group, Soil, Plant and Ecological Sciences, Lincoln University, PO Box 84, \\ Lincoln, New Zealand \\ Peter B. HeEnAN \\ Landcare Research, PO Box 69, Lincoln, New Zealand \\ Communicating Editor: John Freudenstein

\begin{abstract}
Aвstract. Phylogenetic relationships of New Zealand species of Brassicaceae belonging to the South Island endemic Ischnocarpus, Iti, Notothlaspi, and Pachycladon, and the indigenous Cardamine, Cheesemania, Lepidium, and Rorippa were studied using nuclear ribosomal internal transcribed spacer sequences. Results support a monophyletic Notothlaspi and suggest that species of this genus are not closely related to Thlaspi, the genus to which Hooker provisionally assigned N. australe. The cosmopolitan genus Cardamine is paraphyletic by the inclusion of the monotypic genus Iti. The association of It $i$ with New Zealand Cardamine is of particular significance, as the relationships of this monotypic genus have historically proven elusive. Cheesemania species, Ischnocarpus novae-zelandiae, and Pachycladon novae-zelandiae form a closely related monophyletic group. The species of Lepidium form a monophyletic group, but the New Zealand species are not monophyletic indicating two possible dispersal events to New Zealand. Additionally, the tribes Arabidieae, Lepidieae, and Sisymbrieae are polyphyletic. This study highlights the difficulty of using traditional characters such as fruit type and cotyledon arrangement to define the tribes of the Brassicaceae.
\end{abstract}

The New Zealand Brassicaceae are notable for their high degree of generic endemism, and the few species in each genus. Several endemic genera occur in the mountains of the South Island, including Ischnocarpus O.E.Schulz, Notothlaspi Hook.f., and Pachycladon Hook.f., with two species each (Allan 1961; Molloy et al. 1999), and the monotypic Iti Garn.-Jones et P.N.Johnson (Garnock-Jones and Johnson 1987). Cheesemania O.E.Schulz has five species in the South Island mountains (Heenan and Garnock-Jones 1999), and a single species is endemic to Tasmania (Curtis and Morris 1993). The cosmopolitan Cardamine L. is well represented in New Zealand with about 20-25 species, most of which are unnamed and occur in the South Island mountains (P. B. Heenan unpubl. data). Lepidium L. and Rorippa Scop. are also cosmopolitan. Lepidium in New Zealand includes five coastal and two inland South Island species (Webb et al. 1988; GarnockJones and Norton 1995). Rorippa is represented in New Zealand by two species (Webb et al. 1988).

The taxonomic history of the New Zealand Brassicaceae is complex and, like other groups of New Zealand plants (e.g., Apiaceae, Mitchell et al. 1998), reflects the influence of Northern Hemisphere taxonomists (Garnock-Jones 1991). Most of the New Zealand species were initially placed in well- known or common Northern Hemisphere genera, but as better quality and more plant material became available, these species were placed in new and often exclusively New Zealand genera. Species now assigned to Pachycladon were originally placed in Braya (Hooker 1864, 1867), Ischnocarpus in Sisymbrium L. (Hooker 1864; Schulz 1924), Notothlaspi in Thlaspi L. (Hooker 1855, 1864), and Cheesemania in Arabis L., Cardamine, and Nasturtium R.Br (Hooker 1855, 1864; Cheeseman 1925; Schulz 1929). The most recent assessments of the New Zealand genera have been provided by Garnock-Jones and Johnson (1987) where the relationships of Iti were considered, and in a study of seed anatomy and morphology (Garnock-Jones 1991). Seed characters indicate a possible relationship between Ischnocarpus and Pachycladon, whereas the seeds of Cheesemania, Notothlaspi, and Iti are more distinctive (GarnockJones 1991). Apart from these studies the group has been neglected.

The tribal classification of the Brassicaceae is also problematic because the characters traditionally used at this rank are few in number and may not support natural groups (Vaughan and Whitehouse 1971; Hedge 1976; Al-Shehbaz 1988). Traditionally important characters include the orientation of the radicle in the embryo, the number of rows of seeds 
in each locule of the silique, flower color, trichome types, and features of the nectaries. Currently, $\mathrm{Pa}$ chycladon, Ischnocarpus, and Iti are placed in the tribe Sisymbrieae, Cheesemania and Cardamine in the tribe Arabideae, and Lepidium and Notothlaspi in the Lepidieae (Schulz 1924; Garnock-Jones and Johnson 1987; Webb et al. 1988). The presence of incumbent or accumbent cotyledons has been a particularly important character for tribal classification. However, this character can be polymorphic within a species, as has been shown for Cheesemania enysii (Cheeseman) O.E.Schulz, C. fastigiata (Hook.f.) O.E.Schulz, C. latesiliqua (Cheeseman) O.E.Schulz, and C. stellata (Allan) Heenan et Garn.-Jones, where both incumbent and accumbent cotyledons can be found (Garnock-Jones 1991; Heenan and GarnockJones 1999).

The New Zealand Brassicaceae have not previously been studied using phylogenetic methods; although the named genera include species of similar growth habit and morphology, their affinities are poorly understood. This study poses two questions: (1) What are the relationships among the New Zealand genera and species? (2) Can monophyletic groups be circumscribed that include these taxa? To resolve these questions, phylogenetic analysis of nucleotide sequences of the internal transcribed spacers (ITS) of nuclear ribosomal DNA was employed.

\section{Materials AND MethodS}

Plant Materials. The study group consisted of representatives of all New Zealand genera of Brassicaceae, including four species of Cardamine (New Zealand species are currently under revision by $\mathrm{P}$. B. Heenan), five of Lepidium, four of Cheesemania, two of Ischnocarpus, two of Pachycladon, one of Rorippa, two species and one possible undescribed species of Notothlaspi, and the monotypic Iti (Table 1). This sampling included four out of the five endemic species of Cheesemania, five out of seven endemic species of Lepidium, and one each of the two species of Pachycladon and Rorippa. Brassicaceae from outside of New Zealand, and from the tribes to which the New Zealand taxa belong, have been included to provide a broader context for relationships of the New Zealand genera. The taxa included in this study are listed in Table 1 with details of their provenance, herbarium voucher (CHR), and GenBank accession number. Twenty-three New Zealand species were sequenced and an additional 20 sequences were obtained from GenBank.
DNA Analysis. Total DNA was extracted from fresh leaf tissue or dried leaves stored in silica gel, although herbarium material was also used as a source of DNA for analysis (Table 1). Total DNA was extracted using a modification of the CTAB method (Doyle and Doyle 1987). Initially $0.5 \mu \mathrm{l}$ of the total DNA extract (diluted 1:500) was used as a template for the amplification of double-stranded DNA (dsDNA) in a thermocycler. Excess primers and salts were removed by precipitation with isopropanol in the presence of $2.5 \mathrm{M} \mathrm{NH}_{4} \mathrm{Ac}$ followed by a $70 \% \mathrm{EtOH}$ wash. Both the forward and reverse strands of the ITS-1, 5.8S, and ITS-2 regions of nuclear encoded ribosomal DNA were sequenced according to the methods of Baldwin (1992). Primers used were ITS4 and ITS5 (White et al. 1990) as well as FFB (5'- TATGCTTAAATTCAGGGGGT -3') and 18D (5' -CACACCGCCCGTCGCTCCTACCGATTG $-3^{\prime}$ ). The purified PCR fragments were sequenced using the ABI BigDye cycle sequencing kit and run on an $\mathrm{ABI} 373$ automated sequencer.

Sequences were aligned using Clustal $\mathrm{W}$ vers. 1.6 (Thompson and Gibson 1996), then confirmed manually using sequential pairwise comparisons. The aligned data used in this analysis are available from the first author upon request. Gaps were created to ensure positional homology in instances where an insertion or deletion event may have occurred, and gaps were coded as missing data. The $5.8 \mathrm{~S}$ region was not available in some of the sequences obtained from GenBank; these were coded as missing data. The 'Filter Taxa' option was used in MacClade vers. 3.1 (Maddison and Maddison 1992), where taxa were considered redundant even if states were not identical, when the resolution of missing or uncertain data made them potentially identical.

Phylogenetic Analyses. Analyses were conducted using PAUP vers. 3.1.1 (Swofford 1993) and the Maximum Likelihood program DNAML, from PHYLIP vers. 3.5c (Felsenstein 1993). Data were analysed as unordered characters using the heuristic search and the random addition sequence (10 replicates) options in PAUP. TBR branch swapping, COLLAPSE and MULPARS options were in effect. No characters were excluded, all characters were equally weighted, and branch lengths of 0 were collapsed to polytomies. A strict consensus tree of equally parsimonious trees (Sokal and Rohlf 1981) was constructed to assess the information that was common all most parsimonious trees. Bootstrap values (Felsenstein 1985) were calculated from 500 replicate parsimony analyses, using the simple addition sequence of taxa and the heuristic search op- 


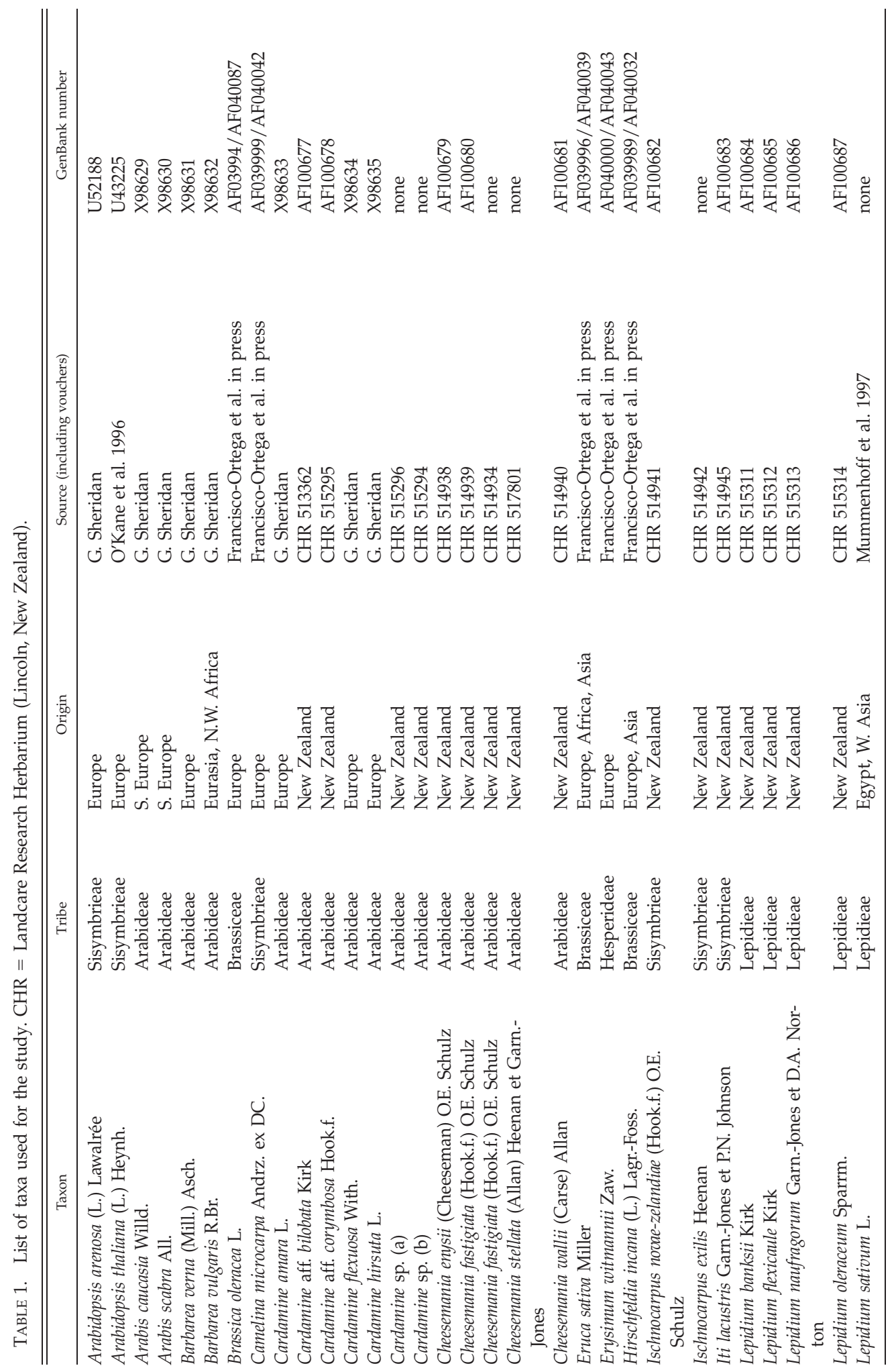




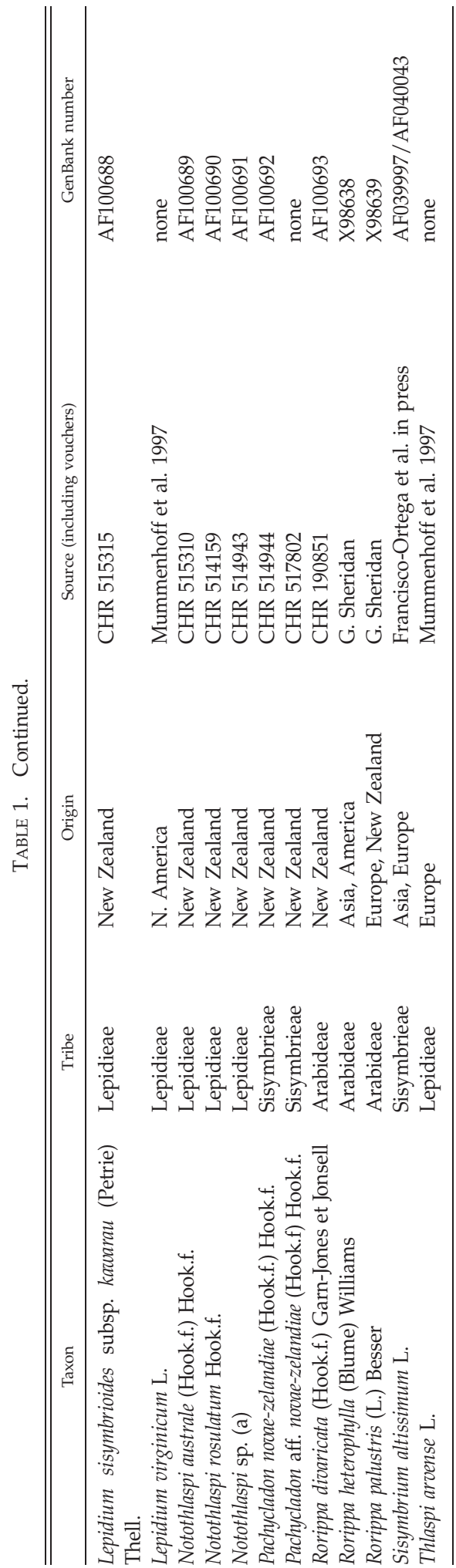

tion in PAUP. The data set was jumbled for Maximum Likelihood analysis, which was carried out with a transition:transversion ratio of 1.3 , estimated from the most parsimonious trees using MacClade. Taxa from the tribe Brassiceae were designated as the root for trees, as this tribe is considered one of the most natural in the Brassicaceae (Avetisian 1976, 1983; Al-Shehbaz 1984). Three parsimony analyses were conducted using topological constraints enforcing the monophyly of species from tribes Arabideae, Sisymbrieae, and Lepidieae respectively, and tree lengths were compared with those obtained from unconstrained analysis.

\section{RESULTS}

Taxa merged as a result of applying the FILTER TAXA option in MacClade were: (1) Cardamine aff. corymbosa + Cardamine sp. (a) + Cardamine sp. (b); (2) Cheesemania fastigiata + Cheesemania stellata + Cheesemania aff. fastigiata, and (3) Ischnocarpus novaezelandiae + Ischnocarpus exilis, and (4) Pachycladon novae-zelandiae + Pachycladon aff. novae-zelandiae. These merged taxa were eliminated from the analysis and are represented in Fig. 1 by Cardamine aff. corymbosa, Cheesemania fastigiata, Ischnocarpus novaezelandiae, and Pachycladon novae-zelandiae, respectively. The resulting matrix used for analysis contained a total of 37 taxa, representing five Brassicaceae tribes (Table 1). A total of 661 nucleotide positions were included in the analysis. The nucleotide composition was $22.4 \% \mathrm{~A}, 28.3 \% \mathrm{C}, 26.8 \% \mathrm{G}, 22.5 \% \mathrm{~T}$, with 355-385 unambiguous transitions and 313-343 unambiguous transversions, calculated in MacClade using the RESOLVE POLYTOMY option. The PAUP analysis yielded 13 equally parsimonious trees, each 698 steps long, with a consistency index (CI) of 0.619 and a rescaled consistency index (RC) of 0.481 . Of the 661 characters included in the analysis, 196 were phylogenetically informative. The log likelihood index $(\ln )=-4675.04$.

The New Zealand genera occur in four major monophyletic groups (Fig. 1). The first includes Arabidopsis species, Camelina microcarpa, Cheesemania species, Ischnocarpus novae-zelandiae, Pachycladon novae-zelandiae, and Erysimum witmannii; the second comprises all Lepidium species sampled, the third includes Barbarea species, Cardamine species, Iti lacustris, and the Rorippa species; and the fourth includes Notothlaspi. Bootstrap analysis indicates that the monophyly of these groups is well supported. Except for the resolved relationships of Cheesemania 

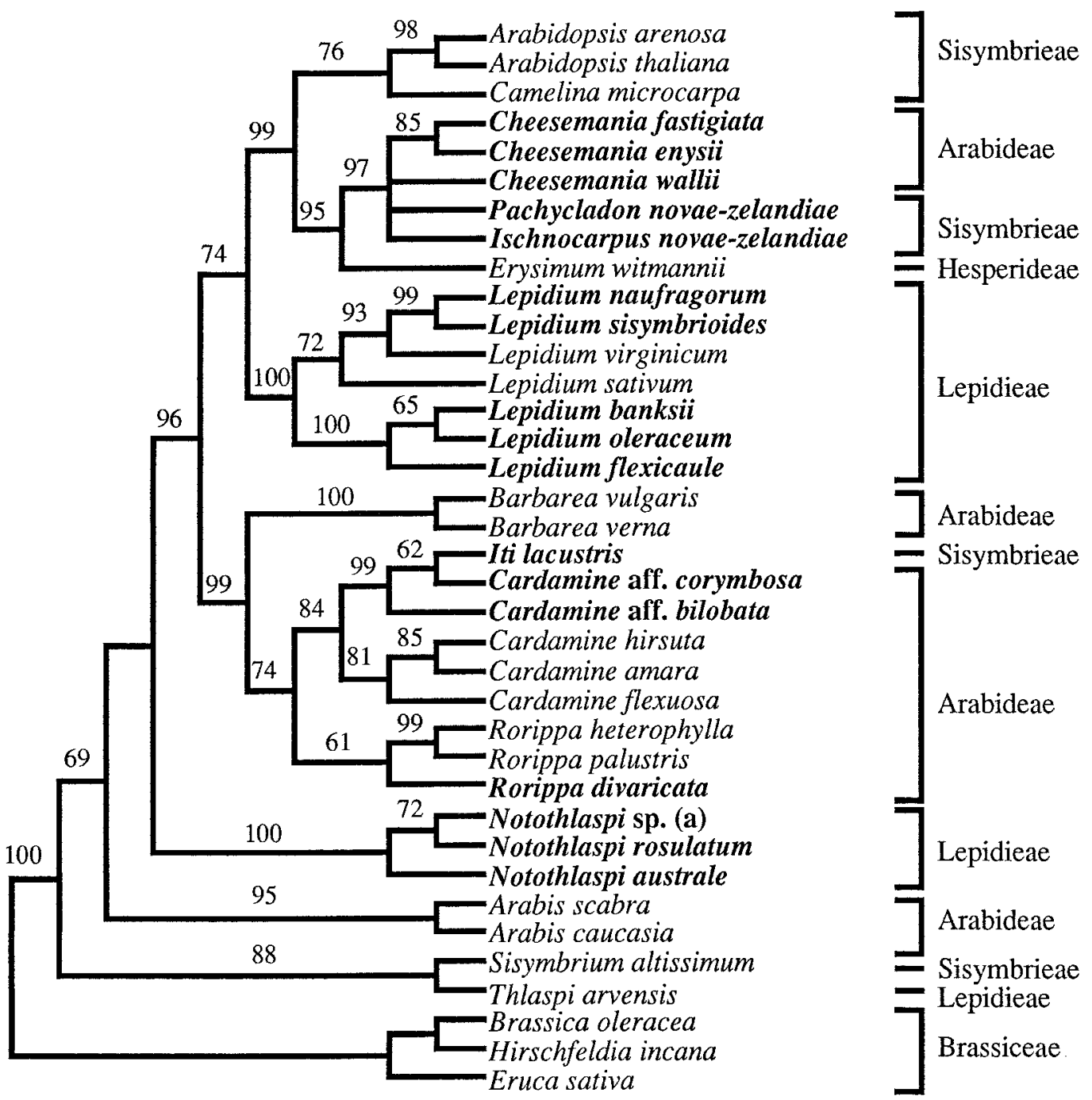

FIG. 1. Strict consensus of 13 equally parsimonious trees constructed from ITS sequence data, of 698 steps, with a consistency index $(\mathrm{CI})=0.619$ and rescaled consistency index $(\mathrm{RC})=0.481$. Species endemic to New Zealand are highlighted.

species, Ischnocarpus novae-zelandiae and Pachycladon novae-zelandiae in the maximum likelihood tree, which collapsed in the strict consensus parsimony tree, the topologies are identical (Fig. 1).

Trees 75 steps longer than the most parsimonious trees were found when topological constraints were imposed that placed species from the tribe Sisymbrieae together. Similarly, when species from the Arabideae were constrained to monophyly, the resulting trees were 59 steps longer. When species from the Lepidieae were constrained, trees were 19 steps longer.

\section{DISCUSSION}

Phylogenetic analyses of the DNA data provide significant new insights into relationships among New Zealand genera of the Brassicaceae, which were found to occur in five separate clades. These include: (1) Notothlaspi; (2) Lepidium; (3) Cardamine + Iti; (4) Rorippa; (5) Cheesemania + Ischnocarpus + Pachycladon.

Notothlaspi, Lepidium, and the Asian/European Thlaspi share angustiseptate silicles and have traditionally been placed in the tribe Lepidieae (Schulz 
1936). However, our results (Fig. 1) do not support monophylly of the Lepidieae, with genera from this tribe occurring in distinct clades composed of other Brassicaceae tribes. New Zealand endemic species of Lepidium constitute two different but related lineages, from which it may be inferred that there have been at least two dispersals and colonizations of Lepidium to New Zealand. Lepidium virginicum and L. sativum (found in the Northern Hemisphere) are inferred to have diverged prior to the New Zealand endemic Lepidium sisymbrioides and L. naufragorum. The sister group to these species includes the other New Zealand endemics L. flexicaule, $L$. banksii, and L. oleraceum. The three species of Notothlaspi form a monophyletic group with no close affinities to other Lepidieae (Fig. 1). In particular, our results suggest Notothlaspi is not closely related to Thlaspi, the genus to which Hooker provisionally assigned the species $N$. australe when it was first described (Hooker 1855, "Thlaspi? Australe"). Notothlaspi has been placed in its own subtribe, the Notothlaspidinae (Schulz 1936).

The cosmopolitan genus Cardamine was found to be paraphyletic by the inclusion of the monotypic genus Iti (Fig. 1). However, New Zealand Cardamine and Iti form a monophyletic group, which is sister group to other species of Cardamine, and are closely related to the Australian C. lilacina (Franzke et al. 1998). The association of Iti with New Zealand Cardamine is of particular significance as the relationships of this monotypic genus have proven elusive (Garnock-Jones and Johnson 1987; Garnock-Jones 1991; Garnock-Jones and Breitwieser 1998). Iti has small flowers, narrow usually simple leaves, sparse indumentum, barely dehiscent fruits, and embryos with elongated cotyledons (Garnock-Jones and Johnson 1987). These characters could be regarded as adaptations to its lake-shore habitat, since some of these characters it shares with unrelated species that occupy similar habitats in New Zealand (Wagstaff and Garnock-Jones 1998). Characters in Iti that could indicate relationships with other New Zealand Brassicaceae, particularly with Cardamine, may have been lost, e.g., Iti lacks recoiling valves and explosive fruit dehiscence, which have been considered synapomorphies for Cardamine (Garnock-Jones and Breitwieser 1998). However, the possibility of a relationship between It $i$ and Cardamine has been previously suggested (Garnock-Jones and Breitwieser 1998), and the chromosome numbers for both It $i$ and New Zealand Cardamine are $2 n=48$ (Pritchard 1957; Garnock-Jones and Johnson 1987). Iti has incumbent cotyledons and an oblong sil- icle and was, therefore, placed in the Sisymbrieae (following Schulz 1936 and Janchen 1942), and compared with Ischnocarpus and Pachycladon (GarnockJones and Johnson 1987). However, the placement of It $i$ with other taxa from the Sisymbrieae was not supported in this analysis (Fig. 1), and its incumbent cotyledons appear to be a derived condition within the group that included representatives from the tribe Arabideae, which otherwise has accumbent cotyledons. The Sisymbrieae, as circumscribed using traditional characters, are therefore polyphyletic.

The monophylly of Cheesemania, Ischnocarpus, and Pachycladon (Fig. 1) conflicts with hypotheses of relationships proposed by Schulz (1924, 1929, 1936). The presence of accumbent cotyledons is traditionally used to define the Arabideae, while incumbent cotyledons are used to define the Sisymbrieae (Schulz 1936; Al-Shehbaz 1984). Cheesemania is presently classified in the Arabideae, with species previously assigned to Arabis, Cardamine, and Nasturtium (Schulz 1929, 1936). However, Cheesemania has polymorphic cotyledons that may be incumbent, accumbent, obliquely accumbent, and/or obliquely incumbent (Garnock-Jones 1991; Heenan and Garnock-Jones 1999). Polymorphism of the cotyledon in Cheesemania is derived since the closely related Ischnocarpus and Pachycladon, and the more distantly related Erysimum, Arabidopsis, and Camelina, all possess incumbent cotyledons.

Ischnocarpus and Pachycladon historically have been placed in different subtribes of the Sisymbrieae (Schulz 1924, 1936). However, Ischnocarpus and Pachycladon share several characters that may support a close relationship, some of which occur elsewhere in the Brassicaceae. These include chromosome numbers of $2 n=20$ (Dawson 1995; M. I. Dawson, unpubl. data), branched or dendritic hairs on the leaves and inflorescences, introrse anthers, a papillate stigma, inflorescences with lateral branches, and septa with a prominent midvein. Cheesemania is most similar to Pachycladon, sharing a stout caudex and seeds in two rows in each locule. The inflorescences of Cheesemania are either lateral (C. wallii) and/or terminal (other Cheesemania species), the pod valves are generally flat, and the anthers are usually at a similar height to the stigma at anthesis. Exceptions are the siliques of $C$. wallii being slightly keeled, and the anthers in C. latesiliqua held well beyond the stigma.

The seeds of Ischnocarpus and Pachycladon are similar in sharing a single reticulation formed of epidermal cells, large rounded mucilage bodies vir- 
tually filling the epidermal cells, thin-walled palisade which does not collapse, a well-defined aleurone layer, and imbricate radicles (Garnock-Jones 1991). Pachycladon has larger seeds and more numerous areoles than Ischnocarpus. The seeds of New Zealand species of Cheesemania differ from these two genera in being winged (Garnock-Jones 1991). Based on seed anatomy, it is difficult to infer a relationship between Ischnocarpus/Pachycladon and Cheesemania.

Additional support for the relationship between Ischnocarpus and Pachycladon is provided by artificial intergeneric $F_{1}$ and $F_{2}$ hybrids between the two genera (Heenan 1999), and the issue of merging Ischnocarpus and Pachycladon as members of the same genus is under consideration. The ITS data support a close relationship of these two genera with Cheesemania. However, before any generic changes are made, it is necessary to identify characters that adequately circumscribe the expanded generic concept. In addition, the possible inclusion of some of the endemic Australian Brassicaceae in this clade needs to be considered before generic boundaries are redrawn.

The New Zealand endemic Rorippa divaricata (Garnock-Jones and Jonsell 1988) formed a monophyletic clade with the other species of Rorippa (Fig. 1). Rorippa divaricata fits within the current circumscription of Rorippa (Al-Shehbaz and Price 1998), but is part of a group of taxa from Australasia, New Guinea, and the west Pacific with white petals, linear siliques, and large reticulate seeds that has been recognized at the sectional rank as Nasturtium sect. Ceriosperma (Schulz 1933). It has been suggested that this section could be raised to generic rank (Garnock-Jones 1978), and their distinct testa morphology and anatomy might provide some support for this view (P. J. Garnock-Jones and B. Jonsell pers. comm.). The phylogenetic relationships within Rorippa presented here indicate that additional species should be examined to establish whether sect. Ceriosperma is sister to Rorippa s.s.

Erysimum witmannii, the only representative of the Hesperideae included in this study, was found to be sister to species traditionally classified in the Sisymbrieae and Arabideae (Schulz 1936) (Fig. 1). However, the relationships of the Hesperideae historically have been problematic (Al-Shehbaz 1984), with Janchen (1942) merging it with the Matthioleae, and Avetisian $(1976,1983)$ including it in the Sisymbrieae. Our results are congruent with the classification proposed by Avetisian, but this should be tested by the inclusion of additional species representative of the Hesperideae.
Based only on this phylogenetic study of ITS data it could be argued that Iti should be included in Cardamine, and perhaps that Cheesemania, Ischnocarpus, and Pachycladon be placed in a single genus. However, a general lack of agreement between molecular data and morphological characters makes taxonomic interpretation difficult, and further work is needed prior to making any taxonomic changes. In particular, Australian genera, whose affinities are also poorly known, should be included in future work. This study has highlighted the difficulty of using fruit type and cotyledon arrangement for defining tribes of the Brassicaceae.

ACKNOWLedgments. We thank G. E. C. Sheridan, M. Chase, D. Blakesley, and J. M. Clarkson for permission to use their unpublished Brassicaceae sequences; Grant Bawdon and Steve Benham for providing plant material; and Phil Garnock-Jones, Steve Wagstaff, Javier Francisco-Ortega, and an anonymous reviewer for criticism of the draft manuscript. Funds for the research were provided in part by the Foundation for Research, Science and Technology under contract C09618.

\section{Literature Cited}

Allan, H. H. 1961. Flora of New Zealand. Vol. I. Wellington: Government Printer.

Al-Shenbaz, I. 1984. The tribes of Cruciferae (Brassicaceae) in the southeastern United States. Journal of the Arnold Arboretum 65: 343-373.

- 1988. The genera of the Arabideae (Cruciferae; Brassicaceae) in the Southeastern United States. Journal of the Arnold Arboretum 69: 85-166.

— and R. A. PRICE. 1998. Delimitation of the genus Nasturtium (Brassicaceae). Novon 8: 124-126.

Avetisian, V. E. 1976. Some modifications of the system of the family Brassicaceae. Botaničeskij Zhurnal 61: 1198-1203.

- 1983. The system of the family Brassicaceae. Botaničeskij Zhurnal 68: 1297-1305.

BALDWIN, B. G. 1992. Phylogenetic utility of the internal transcribed spacers of nuclear ribosomal DNA in plants: An example from the Compositae. Molecular Phylogenetics and Evolution 1: 3-16.

Cheeseman, T. F. 1925. Manual of the New Zealand Flora. 2nd ed. Wellington: Government Printer.

Curtis, W. M. and D. I. Morris. 1993. The Student's Flora of Tasmania. Part 1. 2nd ed. Hobart: St. David's Park Publishing.

DAwsON, M. I. 1995. Contributions to a chromosome atlas of the New Zealand flora 33. Miscellaneous species. New Zealand Journal of Botany 33: 477-487.

DoYLE, J. J. and J. L. DoYLE. 1987. A rapid DNA isolation procedure for small quantities of fresh leaf tissue. Phytochemical Bulletin 19: 11-15.

Felsenstein, J. 1985. Confidence limits on phylogenies: an approach using the bootstrap. Evolution 39: 783-791. 
1993. PHYLIP (Phylogeny Inference Package) version 3.5c. Seattle: Department of Genetics, University of Washington.

Francisco-Ortega, J., J. Fuertes-Aguilar, C. GomezCampo, A. Santos-Guerra, and R. K. Jansen. In press. ITS sequence phylogeny of Crambe L. (Brassicaceae): Molecular data reveal two Old World disjunctions. Molecular Phylogenetics and Evolution.

FranzKe, A., K. Pollmann, W. Bleeker, R. Kohrt, and H. HURKA. 1998. Molecular systematics of Cardamine and allied genera (Brassicaceae): ITS and non-coding chloroplast DNA. Folia Geobotanica 33: 225-240.

GARNOCK-JonES, P. J. 1978. Rorippa (Cruciferae, Arabideae) in New Zealand. New Zealand Journal of Botany 16: 119-122.

- 1991. Seed morphology and anatomy of the New Zealand genera Cheesemania, Ischnocarpus, Iti, Notothlaspi, and Pachycladon (Brassicaceae). New Zealand Journal of Botany 29: 71-82.

- and I. BREITWIESER. 1998. New Zealand floras and systematic botany: progress and prospects. Australian Systematic Botany 11: 175-184.

_ and P. N. JOHNSON. 1987. Iti lacustris (Brassicaceae), a new genus and species from southern New Zealand. New Zealand Journal of Botany 25: 603-610.

- and B. JONSELL. 1988. Rorippa divaricata (Brassicaceae): a new combination. New Zealand Journal of Botany 26: 479-480.

- and D. A. NORTON. 1995. Lepidium naufragorum (Brassicaceae), a new species from Westland, and notes on other coastal species of Lepidium. New Zealand Journal of Botany 33: 43-51.

HedGE, I. C. 1976. A systematic and geographical survey of the old world Cruciferae. Pp. 1-35 in The Biology and Chemistry of the Cruciferae, eds. J. G. Vaughan, A. J. McLead, and B. M. G. Jones. London: Academic Press.

HeEnan, P. B. 1999. Artificial intergeneric hybrids between the New Zealand endemic Ischnocarpus and Pachycladon (Brassicaceae). New Zealand Journal of Botany 37: 595-601.

— and P. J. GARNOCK-JONES. 1999. A new species combination in Cheesemania (Brassicaceae). New Zealand Journal of Botany 37: 235-241.

HOOKER, J. D. 1855. The Botany of the Antarctic Voyage. II. Flora Novae-Zelandiae. Part II. Flowerless plants. London: Reeve and Co.

-1864. Handbook of the New Zealand Flora. Part 1. London: Reeve and Co.

- 1867. Handbook of the New Zealand Flora. Part 2. London: Reeve and Co.

JANCHEN, E. 1942. Das System der Cruciferen. Oesterreichische Botanische Zeitschrift 91: 1-28.

MAdDison, W. P. and D. R. MAdDison. 1992. MacClade vers. 3.1: Analysis of Phylogeny and Character Evolution. Sunderland, Massachusetts: Sinauer Associates.

Mitchell, A. D., C. J. WebB, and S. J. Wagstaff. 1998. Phylogenetic relationships of species of Gingidia and related genera (Apiaceae subfamily Apioideae). New Zealand Journal of Botany 36: 417-424.

Molloy, B. P. J., E. Edgar, P. B. HeEnan, and P. J. De LANGE. 1999. New species of Poa (Gramineae) and Ischnocarpus (Brassicaceae) from limestone, North Otago, South Island, New Zealand. New Zealand Journal of Botany 37: 41-50.

Mummenhoff, K., A. FranzKe, and M. Koch. 1997. Molecular phylogenetics of Thlaspi s.l. (Brassicaceae) based on chloroplast DNA restriction site variation and sequences of the internal transcribed spacers of nuclear ribosomal DNA. Canadian Journal of Botany 75: 469-482.

O'Kane, S., B. A. SchaAl, and I. A. Al-Shehbaz. 1996. The origins of Arabidopsis suecica (Brassicaceae) as indicated by nuclear rDNA sequences. Systematic Botany 21: 559-566.

Pritchard, G. G. 1957. Experimental taxonomic studies on species of Cardamine Linn. in New Zealand. Transactions of the Royal Society of New Zealand 85: 7589.

Schulz, O. E. 1924. Cruciferae-Sisymbrieae. Pp. 1-388 in Das Pflanzenreich IV 105 (Heft 86), ed. A. Engler. Berlin: Wilhelm Engelmann.

- 1929. Cheesemania, eine neue australische Cruciferengattung. Notizblatt des Botanischen Gartens und Museums zu Berlin-Dahlem 10: 551-553.

. 1933. Kurze Notizen über neue Gattungen, Sektionen und Arten der Cruciferen. Botanische Jahrbücher für Systematik, Pflanzengeschichte und Pflanzengeographie 66: 91-102.

- 1936. Cruciferae. Pp. 227-658 in Die Natürlichen Pflanzenfamilien, ed. 2, 17B, eds. A. Engler and K. Prantl. Leipzig: Wilhelm Engelmann.

SOKAL, R. R. and F. J. RoHLF. 1981. Taxonomic congruence in the Leptodomorpha reexamined. Systematic Zoology 30: 309-325.

SWOFFORD, D. L. 1993. Phylogenetic analysis using parsimony (PAUP vers. 3.1.1). Champaign: Illinois Natural History Survey.

ThOMPSON, J. and T. GiBSON. 1996. Clustal W version 1.6. Heidelberg, Germany: European Molecular Biology Laboratory.

VAughan, J. G. and J. M. Whitehouse. 1971. Seed structure and the anatomy of the Cruciferae. Botanical Journal of the Linnean Society 64: 383-409.

WAGSTAFF, S. J. and P. J. GARNOCK-JONES. 1998. Evolution and biogeography of the Hebe complex (Scrophulariaceae) inferred from ITS sequences. New Zealand Journal of Botany 36: 425-437.

WebB, C. J., W. R. SYKeS, and P. J. GARNOCK-JONES. 1988. Flora of New Zealand IV. Christchurch: DSIR Botany Division.

White, T. J., T. Bruns, S. LeE, and J. TAYlor. 1990. Amplification and direct sequencing of fungal ribosoaml RNA genes for phylogenetics. Pp. 315-324 in PCR Protocols: A Guide to Methods and Applications, eds. M. A. Innis, D. H. Gelfand, J. J. Sninsky and T. J. White. San Diego: Academic Press. 